\title{
Current treatment options for the management of esophageal cancer
}

This article was published in the following Dove Press journal:

Cancer Management and Research

I November 2012

Number of times this article has been viewed

\section{Mark R Mawhinney \\ Robert E Glasgow \\ Department of Surgery, Huntsman Cancer Institute at the University of Utah, Salt Lake City, UT, USA}

Correspondence: Robert E Glasgow Department of Surgery, University of Utah, 30 North, 1900 East.

Salt Lake City, UT, USA

$\mathrm{Tel}+$ I 8015856035

Fax + I 80I 5879370

Email robert.glasgow@hsc.utah.edu
Abstract: In recent years, esophageal cancer characteristics and management options have evolved significantly. There has been a sharp increase in the frequency of esophageal adenocarcinoma and a decline in the frequency of squamous cell carcinoma. A more comprehensive understanding of prognostic factors influencing outcome has also been developed. This has led to more management options for esophageal cancer at all stages than ever before. A multidisciplinary, team approach to management in a high volume center is the preferred approach. Each patient should be individually assessed based on type of cancer, local or regional involvement, and his or her own functional status to determine an appropriate treatment regimen. This review will discuss management of esophageal cancer relative to disease progression and patient functional status.

Keywords: esophageal adenocarcinoma, squamous cell carcinoma, treatment regimen, disease progression, patient functional status

\section{Background}

Esophageal cancer is a highly lethal disease. The incidence and mortality from cancer of all types in the United States has decreased during the 1991-2006 timeframe. ${ }^{1}$ However, the opposite is true for esophageal cancer. Its incidence and mortality continue to rise. In 2010, estimated new cases of esophageal cancer number 16,640 in the United States, while deaths total $14,500 .{ }^{1}$ The growth in esophageal cancer is attributable to a profound, steady increase in the incidence of esophageal adenocarcinoma. As recently as the 1960s, squamous cell carcinoma accounted for $90 \%$ of esophageal cancers. In 1973, there were 3.6 cases per million people, almost entirely of the squamous cell histology. By 2006, the incidence had grown to 25.6 per million people, reflecting a major shift towards adenocarcinoma histology. The United States has seen an average increase of $20.6 \%$ per year in the incidence of adenocarcinoma of the esophagus since that time. ${ }^{2}$ This translates into a $463 \%$ and $335 \%$ increased incidence in white males and females, respectively, between 1975 and 2004. Adenocarcinoma now accounts for $58 \%$ of all esophageal cancers in the United States. ${ }^{3}$ Despite this profound change in histologic type seen in the United States and Europe, squamous cell carcinoma still accounts for the majority of esophageal cancer diagnoses worldwide, mostly related to its continued prevalence in Asian countries.

This change in the epidemiology of esophageal cancer has contributed to the confusion and controversy in the management of localized esophageal cancer. Most clinical studies in the treatment of esophageal cancer have included both squamous 
and adenocarcinomas. However, it is becoming clear that these entities differ in epidemiology, pathogenesis, and tumor biology. Squamous cell carcinoma is found in the upper two-thirds of the esophagus. It results as a consequence of dysplastic squamous epithelial progression and is strongly associated with cigarette smoking and alcohol ingestion. Adenocarcinoma, on the other hand, is found in the distal one-third of the esophagus and gastroesophageal junction. It is associated with obesity and gastroesophageal reflux and results from metaplastic progression of Barrett's esophagus, which confers a 30-60-fold increase in risk of esophageal adenocarcinoma compared with unaffected individuals. ${ }^{4}$ These differences are just now being clarified, as it relates to staging and treatment of each subtype. Recognizing that these two biologic types of esophageal cancer vary differently, the 2010 American Joint Committee on Cancer (AJCC) separated their TNM classification staging as seen in Table 1. Other major cancer organizations, such as the National Cancer Comprehensive Network (NCCN), are just beginning to separate the entities. ${ }^{6}$ Furthermore, patients with Siewert I or II gastroesophageal junction adenocarcinomas are treated as esophageal cancer, while Siewert III lesions are true gastric cancer tumors and best managed as such. The Siewert tumor classification is summarized in Table 2 and Figure 1.

Unfortunately, only about $50 \%$ of esophageal cancer presents in early stages with localized disease and is amenable to curative treatment. ${ }^{8}$ The other $50 \%$ present with metastatic disease, distant nodal disease outside of the standard treatment field, T4b disease with invasion of the great vessels, heart, or trachea rendering them unresectable, or they occur in a patient too frail to undergo surgical resection or intensive chemoradiation. Survival rates, even in candidates for full multimodality treatment, are still poor, with only $17 \%$ of all patients surviving 5 years; $37 \%$ with localized disease, $19 \%$ with regional nodal involvement, and $3 \%$ or less with distant metastasis. ${ }^{9}$ Multiple advancements have been made to accurately stage and treat patients with esophageal cancer in an effort to better detect and care for those who will benefit most from intervention. This article will explore the current options for management in esophageal cancer. It will be organized according to local disease versus distant disease in the patient fit to tolerate maximum intervention. Patients too frail to undergo therapy should be approached from a palliative perspective.

\section{Prognostic factors}

The most important disease factors influencing patient outcome in esophageal cancer are the depth of tumor
Table I American Joint Committee on Cancer (AJCC) TNM classification of carcinoma of the esophagus and esophagogastric junction. Used with the permission of the American Joint Committee on Cancer (AJCC), Chicago, Illinois. The original source for this material is the AJCC Cancer Staging Manual, Seventh Edition (2010) published by Springer Science and Business Media LLC, www.springer.com ${ }^{5}$

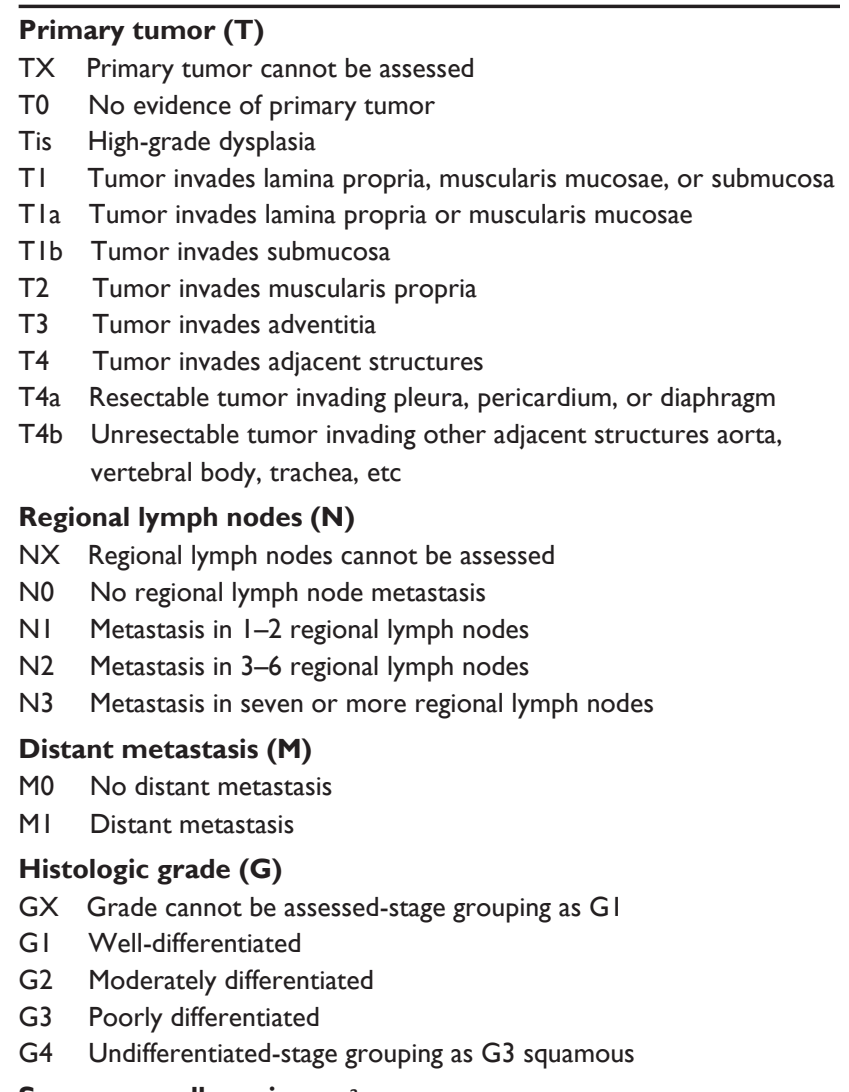
Squamous cell carcinoma ${ }^{a}$

\begin{tabular}{|c|c|c|c|c|c|}
\hline Stage & $\mathbf{T}$ & $\mathbf{N}$ & M & Grade & Tumor location ${ }^{\mathrm{b}}$ \\
\hline \multicolumn{6}{|c|}{ Anatomic stage/prognostic groups } \\
\hline Stage 0 & Tis & No & Mo & $\mathrm{I}, \mathrm{X}$ & Any \\
\hline Stage IA & TI & No & Mo & $\mathrm{I}, \mathrm{X}$ & Any \\
\hline \multirow[t]{2}{*}{ Stage IB } & TI & No & Mo & $2-3$ & Any \\
\hline & $\mathrm{T} 2-3$ & No & Mo & $\mathrm{I}, \mathrm{X}$ & Lower, $\mathrm{X}$ \\
\hline \multirow[t]{2}{*}{ Stage IIA } & $\mathrm{T} 2-3$ & No & Mo & $\mathrm{I}, \mathrm{X}$ & Upper, Middle \\
\hline & $\mathrm{T} 2-3$ & No & Mo & 2,3 & Lower, $\mathrm{X}$ \\
\hline \multirow[t]{2}{*}{ Stage IIB } & $\mathrm{T} 2-3$ & No & Mo & 2,3 & Upper, Middle \\
\hline & TI-2 & NI & Mo & Any & Any \\
\hline \multirow[t]{3}{*}{ Stage IIIA } & TI-2 & N2 & Mo & Any & Any \\
\hline & $\mathrm{T} 3$ & NI & Mo & Any & Any \\
\hline & $\mathrm{T} 4 \mathrm{a}$ & No & Mo & Any & Any \\
\hline Stage IIIB & T3 & N2 & Mo & Any & Any \\
\hline \multirow[t]{3}{*}{ Stage IIIC } & $\mathrm{T} 4 \mathrm{a}$ & $\mathrm{NI}-2$ & Mo & Any & Any \\
\hline & $\mathrm{T} 4 \mathrm{~b}$ & Any & Mo & Any & Any \\
\hline & Any & N3 & Mo & Any & Any \\
\hline Stage IV & Any & Any & MI & Any & Any \\
\hline \multicolumn{6}{|c|}{ Adenocarcinoma } \\
\hline Stage & & $\mathbf{T}$ & $\mathbf{N}$ & $M$ & Grade \\
\hline Stage 0 & & Tis & No & Mo & $\mathrm{I}, \mathrm{X}$ \\
\hline Stage IA & TI & No & Mo & $\mathrm{I}-2, \mathrm{X}$ & \\
\hline
\end{tabular}

(Continued) 
Table I (Continued)

\begin{tabular}{llllll}
\hline Stage IB & TI & N0 & M0 & 3 & \\
& & T2 & N0 & M0 & I-2, X \\
Stage IIA & T2 & N0 & M0 & $3, X$ & \\
Stage IIB & T3 & N0 & M0 & Any & \\
& & TI-2 & NI & M0 & Any \\
Stage IIIA & TI-2 & N2 & M0 & Any & \\
& & T3 & NI & M0 & Any \\
& & T4a & N0 & M0 & Any \\
Stage IIIB & T3 & N2 & M0 & Any & \\
Stage IIIC & T4a & NI-2 & M0 & Any & \\
& & T4b & Any & M0 & Any \\
& & Any & N3 & M0 & Any \\
Stage IV & Any & Any & MI & Any & \\
\hline
\end{tabular}

Notes: ${ }^{\circ}$ Or mixed histology including a squamous component or NOS; blocation of the primary tumor is defined by the position of the upper (proximal) edge of the tumor in the esophagus.

penetration, presence of nodal disease, and evidence of metastatic progression, as seen in Figure 2. Abysmal 5-year survival rates of $<3 \%$ are seen in patients with metastatic esophageal cancer. As such, patients with evidence of metastases to liver, bone, lung, for example, should be approached with a palliative strategy. More controversy exists with patients who have evidence of nodal disease outside of the field of operative resection, including supraclavicular or periaortic nodal stations. Previously, these cases would have been deemed metastatic and, thus, nonresectable. The 2010 American Joint Committee on Cancer (AJCC) TNM staging manual, however, now considers number of nodes in lieu of nodal station. ${ }^{5}$ That said, most consider nonregional lymph nodes and nodes outside of the standard local-regional treatment field to be equivalent to metastatic disease and, therefore, a contraindication to local-regional

Table 2 Siewert classification of adenocarcinoma of the esophagogastric junction ${ }^{7}$

\section{Type I}

Located $\mathrm{I} \mathrm{cm}$ or more above the esophagogastric junction.

Adenocarcinoma of the distal esophagus which usually arises from an area with specialized intestinal metaplasia of the esophagus (ie, Barrett's esophagus) and which may infiltrate the esophagogastric junction from above.

Type 2

Located $\mathrm{I} \mathrm{cm}$ above to $2 \mathrm{~cm}$ distal to the esophagogastric junction. True carcinoma of the cardia arising from the cardiac epithelium or short segments with intestinal metaplasia at the esophagogastric junction; this entity is also often referred to as "junctional carcinoma."

\section{Type 3}

Located more than $2 \mathrm{~cm}$ below the esophagogastric junction.

Subcardial gastric carcinoma which infiltrates the esophagogastric junction and distal esophagus from below.

Reprinted from Siewert JR, Stein HJ. Classification of adenocarcinoma of the esophagogastric junction. Br J Surg. 1998;85(I I):1457-1459.7 With permission from John Wiley and Sons.

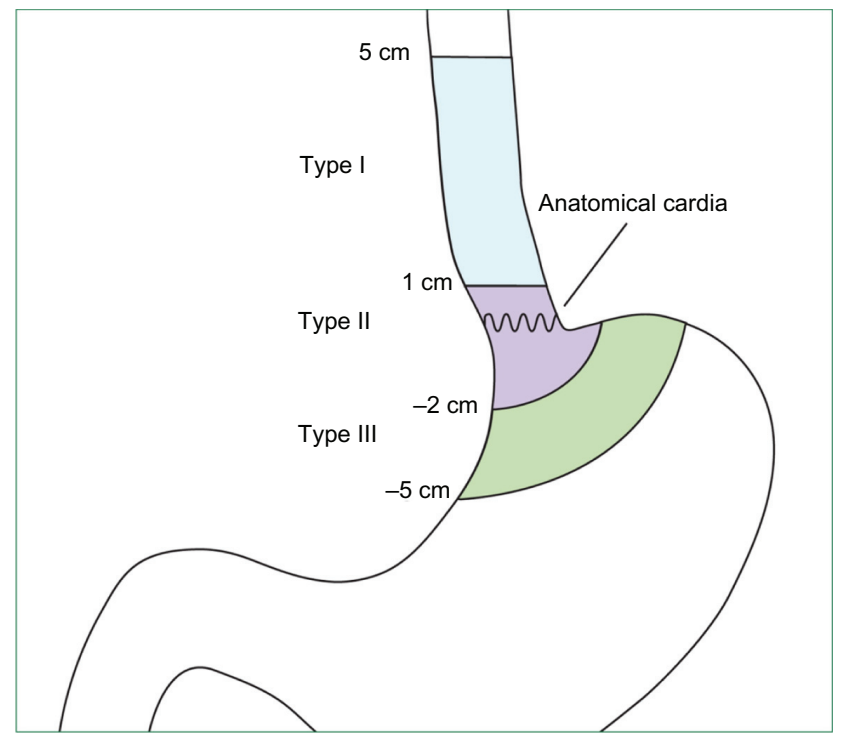

Figure I Schematic illustration of the modified Siewert's classification. Reprinted from Mariette C, Piessen G, Briez N, Gronnier C, Triboulet JP. Oesophagogastric junction adenocarcinoma: which therapeutic approach? Lancet Oncol. 20I I;I2(3): 296-305. ${ }^{61}$ With permission from Elsevier.

measures including surgery. Bulky multistation mediastinal lymphadenopathy is indicative of locoregional advanced disease and a poor prognosis. These patients may, however, benefit from chemoradiation therapy.

In localized esophageal cancer, the extent of tumor invasion into the wall of the esophagus and adjacent tissues (T stage) and nodal involvement ( $\mathrm{N}$ stage) are of critical importance in treatment planning. Direct correlation exists between the depth of invasion and chances of nodal disease presence. As T stage progresses from T1 to T4, the 5-year survival diminishes dramatically, as seen in Figure 3. Specific 5-year survival numbers show T1 69\%, T2 51\%, T3 17\%,

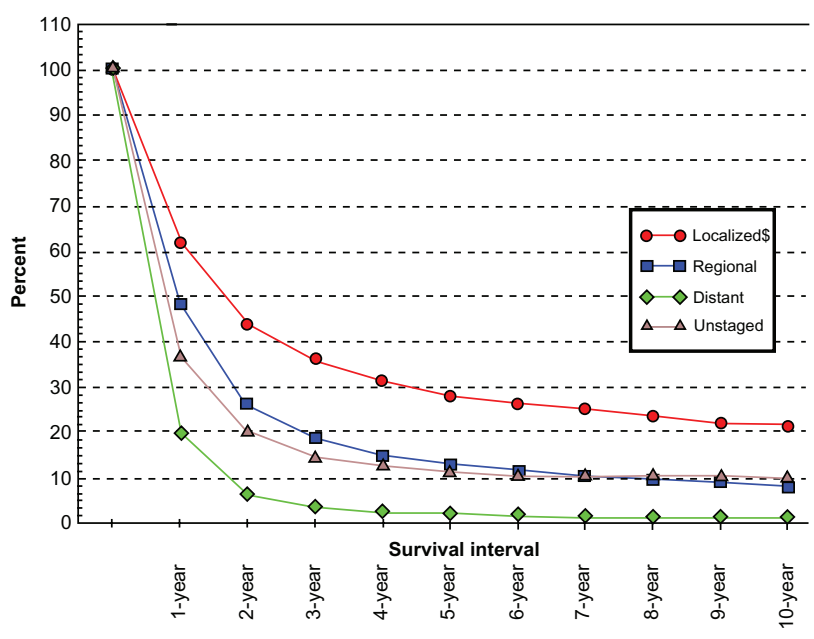

Figure 2 SEER relative survival rates by stage at diagnosis esophagus cancer,all races SEER 9 registries for $1988-2001 .{ }^{58}$ 

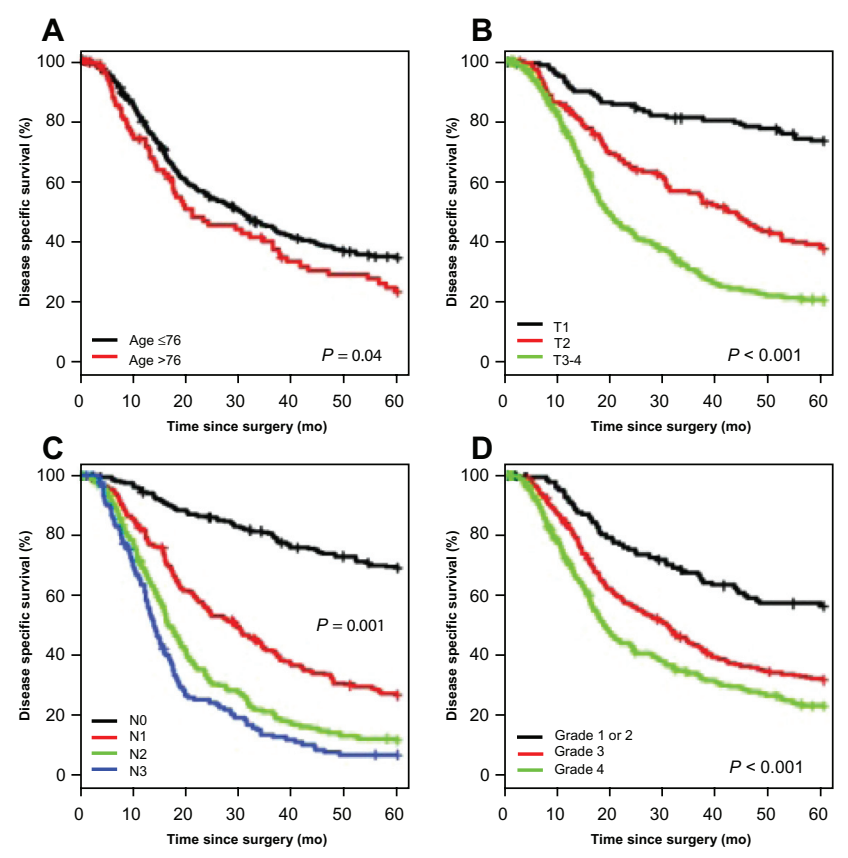

Figure 3 Kaplan-Meier curves for disease-specific survival by age (A), T status (B), $\mathrm{N}$ status (C), and grade (D). Reprinted from Yoon $\mathrm{HH}$, Khan M, Shi Q, et al. The prognostic value of clinical and pathologic factors in esophageal adenocarcinoma: a mayo cohort of 796 patients with extended follow-up after surgical resection. Mayo Clin Proc. 2010;85(12):1080-1089.59 With permission from Elsevier.

and $\mathrm{T} 40 \%{ }^{10}$ Subdividing $\mathrm{T} 1$ disease into $\mathrm{T} 1 \mathrm{a}$ and $\mathrm{T} 1 \mathrm{~b}$ disease further illustrates this relationship. Five-year T1a survival is $88 \%-90 \%$ for lesions that invade the muscularis mucosae and limited by the lamina propria, compared with $47 \%-62 \%$ for $\mathrm{T} 1 \mathrm{~b}$ lesions that invade into the submucosa. ${ }^{11}$ This dramatic decrease in survival is almost certainly related to the increased likelihood of nodal disease.

The risk of lymph node involvement in $\mathrm{T} 1$ disease has recently been evaluated. In $85 \mathrm{~T} 1$ adenocarcinoma specimens, the risk of nodal spread was $0 \%$ in T1a disease, $4 \%$ in $\mathrm{T} 1 \mathrm{~b}$ disease with well/moderate differentiation and no lymphovascular invasion, $22 \%$ in $\mathrm{T} 1 \mathrm{~b}$ disease with poor differentiation and no lymphovascular invasion, and $46 \%$ in any $\mathrm{T} 1 \mathrm{~b}$ with lymphovascular invasion. ${ }^{12}$ Survival parallels lymphovascular invasion. Five-year survival of resected T1 lesions without lymphovascular invasion is $85 \%$, compared with just $36 \%$ with evidence of invasion. In fact, survival in T1b lesions without invasion is similar to T1a lesions at $77 \%$ and $85 \%$ respectively. ${ }^{11}$ The risk of nodal spread can be evaluated in even more detail when examining submucosal relationship. In patients with adenocarcinoma, submucosa level $1(\mathrm{sm}-1)$ disease shows a $0 \%-21 \%$ risk of nodal disease. Sm-2 disease carries a $26 \%-33 \%$ risk, and sm-3 lesions have nodal involvement in $43 \%-67 \%$ of cases. ${ }^{13}$ A similar relationship has been observed for squamous cell histology. ${ }^{14}$
Nodal involvement appears to be the most important prognostic indicator in esophageal cancer, as illustrated in Figure 3. Both the presence of lymph node involvement and the total number of positive nodes correlate with survival. A 2007 study evaluating a single positive lymph node in esophageal cancer resection showed a decrease in median survival from 26 to 16 months. ${ }^{15}$ Overall 5-year survival decreases from $53 \%-55 \%$ in N0 (no regional lymph node metastases) patients to $27 \%-31 \%$ in patients with one or two positive nodes to $6 \%-7 \%$ in patients with three or more positive nodes. ${ }^{10,16}$ The number of positive nodes and not necessarily the location of the nodes has been shown to be important from a prognostic standpoint. Furthermore, the lymph node removal rate or lymph node ratio (metastatic lymph nodes/removed lymph nodes) have also shown to have prognostic significance. ${ }^{17-19}$ As such, the current 2010 AJCC TNM staging system classifies nodal disease as N1 (1-2 nodes), N2 (3-6 nodes), and N3 (7 or more positive nodes). ${ }^{5}$ To appropriately stage a specimen, the AJCC and NCCN recommend at least 15 lymph nodes be examined from a specimen.

The other major variable that significantly influences patient prognosis is the patient's medical fitness for treatment. Each patient should be evaluated with regard to their ability to tolerate chemotherapy, radiation therapy, and major abdominal and thoracic surgery. Significant cardiac and respiratory comorbidities should be evaluated and mitigated. Management of other medical comorbid conditions, like cigarette use, diabetes, and poor nutritional status should be optimized. Patients with malnutrition should receive nutritional support via a nasojejunal or direct jejunostomy feeding tube or self-expanding covered stent. A useful objective measure of performance status is also helpful. Appropriate tools for this purpose include the Karnofsky score and Eastern Cooperative Oncology Group performance status. ${ }^{20,21}$

\section{Staging}

Accurate and complete staging is of critical importance in the management of esophageal cancer. It allows the clinician and patient to make fully informed decisions about pre-, peri-, and postoperative care plans. Ideal staging details all of the AJCC TNM variables of tumor thickness, nodal status, and presence or absence of metastatic disease. Upper endoscopy with biopsy is the typical starting point in the staging workup. The character and location of the lesion within the esophagus should be noted. Pathology should describe the cancer with respect to histopathology and grade. Patients should next go on to receive computed tomography (CT) of the chest (to include the cervical 
region), abdomen, and pelvis. CT scanning can help identify metastatic disease and invasion into adjacent organs that may preclude curative treatment goals. CT has varying ability to detect metastatic disease. It has a sensitivity that ranges between $33 \%$ and $81 \%$ and a specificity of $82 \%-96 \%$. Sensitivity for detecting nodal disease is $47 \%-84 \%$, with specificity of $25 \%-92 \% .{ }^{22,23}$ Positron emission tomography (PET) allows for detection of metastatic disease in up to $15 \%$ of cases missed by conventional CT scanning. ${ }^{24}$ Thus, combination PET/CT is the preferred imaging modality once the diagnosis of esophageal cancer is confirmed by biopsy endoscopically.

Assuming no metastatic disease is found on imaging, the next step in staging is endoscopic ultrasound (EUS). This allows for further characterization of tumor depth and nodal status. EUS is $72 \%-80 \%$ accurate in predicting tumor depth (T stage). ${ }^{25-27}$ EUS also allows for identification of nodal disease with a sensitivity of $63 \%-89 \%$ and a specificity of $75 \%-81 \% .{ }^{23,28,29}$ Biopsy of suspicious nodes can also be performed. It should only be done if it will change management and does not traverse the tissue planes of the primary tumor.

After this workup is complete, the patient should next be presented at a multidisciplinary tumor conference with a defined pretreatment TNM stage. Management then becomes a team effort of surgeons, medical oncologists, radiation oncologists, endoscopists, pathologists, nurses, and support staff. Outcomes are superior for patients treated in high volume specialty centers. ${ }^{30,31}$ This allows a patient to be stratified in several fashions. First, they are determined to have locoregional (stage 1-3) disease versus metastatic (stage 4) disease. Second, it is decided whether the patient with locoregional disease is medically fit for surgery, chemotherapy, and/or radiation therapy. Patients with locoregional disease are then classified as: (1) medically fit and receptive to surgery, chemotherapy, or chemoradiation; (2) medically unfit or unreceptive for surgery but medically fit for chemotherapy or chemoradiation; or (3) unfit for either surgery, chemotherapy, or chemoradiation. Discussion of management options will now be addressed with respect

Table 3 Esophageal cancer survival by stage

\begin{tabular}{llllll}
\hline $\begin{array}{l}\text { Stage } \\
\text { of disease }\end{array}$ & I year & 2 years & 3 years & 4 years & 5 years \\
\hline Stage I & 73.2 & 59.8 & 51.1 & 45.5 & 40.5 \\
Stage 2 & 64.9 & 42.9 & 32.1 & 26.4 & 22.8 \\
Stage 3 & 50.2 & 27.6 & 18.8 & 14.7 & 12.5 \\
Stage 4 & 23.9 & 8.5 & 4.9 & 3.5 & 2.8 \\
\hline
\end{tabular}

Reproduced with permission from American College of Surgeons Cancer Programs. National Cancer Data Base. ${ }^{57}$
A

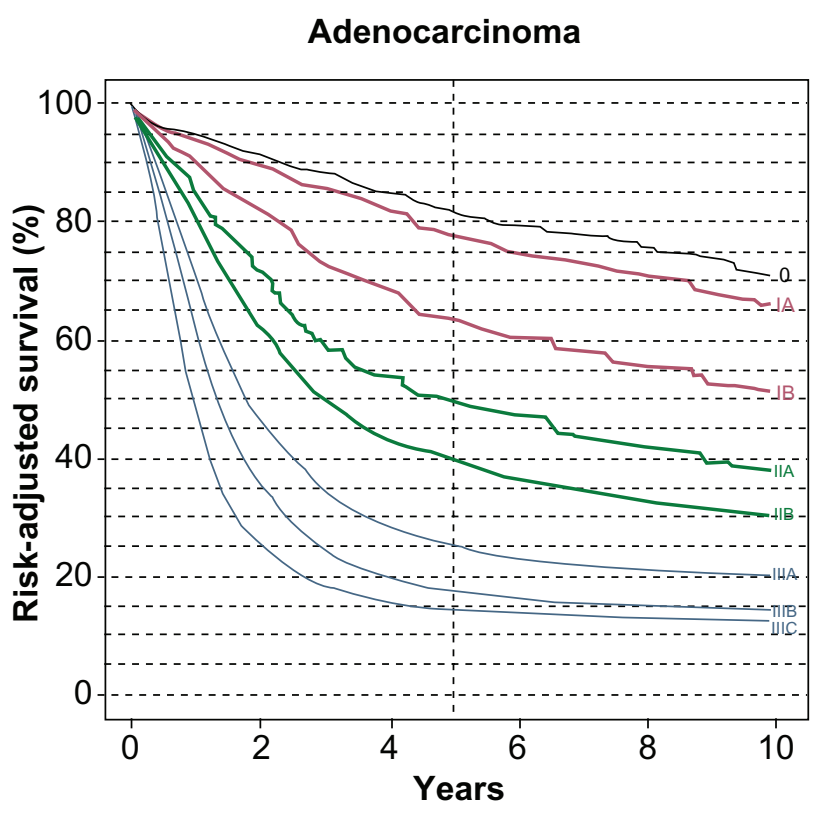

B

\section{Squamous cell carcinoma}

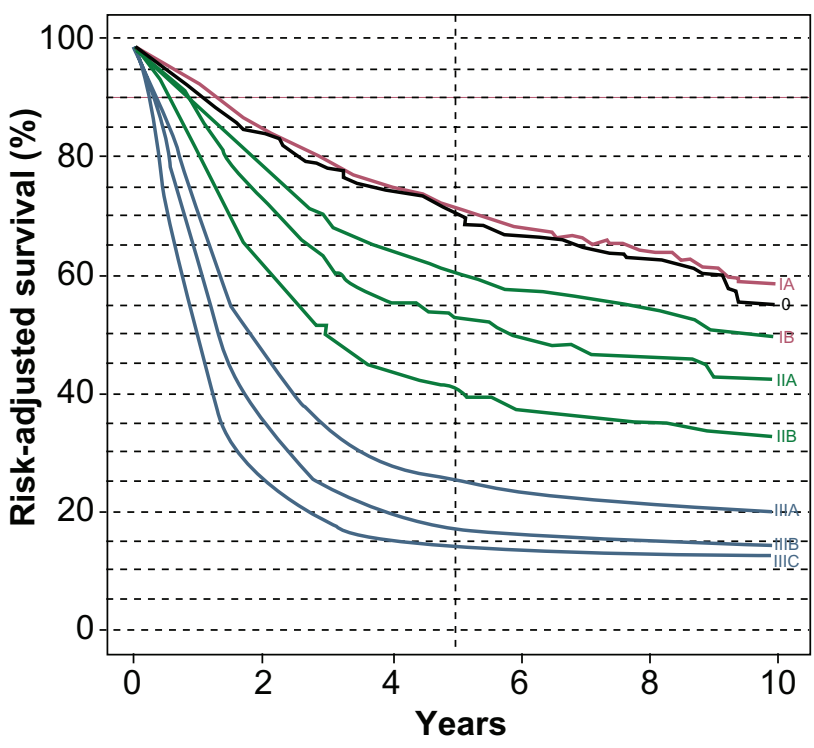

Figure 4 Risk-adjusted survival is illustrated for patients with adenocarcinoma (A) and squamous carcinoma (B) according to stage groups for the 7th edition of the American Joint Committee on Cancer/International Union Against Cancer cancer staging manuals. Reprinted from Rice TW, Rusch VW, Ishwaran H, Blackstone EH; for the Worldwide Esophageal Cancer Collaboration. Cancer of the esophagus and esophagogastric junction: data-driven staging for the seventh edition of the American Joint Committee on Cancer/International Union AgainstCancer Cancer Staging Manuals. Cancer. 2010;1 I6(16):3763-3773. ${ }^{60}$ With permission from John Wiley and Sons.

to localized disease versus distant disease in the medically fit patient. A medically unfit patient should be considered for palliative treatment only. Current stage-specific survival for esophageal cancer is illustrated in Table 3 and Figure 4. 


\section{Principles of chemotherapy}

Combined modality chemoradiation followed by surgery is the preferred treatment of esophageal cancer in patients eligible to receive such therapy. With respect to chemotherapy, in general, regimens used for esophageal/ esophagogastric adenocarcinoma, squamous cell carcinoma of the esophagus, and gastric adenocarcinoma can be used interchangeably. Multiple chemotherapeutic schedules exist for treatment of esophageal and esophagogastric junction cancer. As with surgical intervention and other forms of cancer, patient functional status, comorbidities, and drug side-effect profiles should be considered when tailoring a specific regimen. Further influencing chemotherapeutic agent selection is whether the treatment goal for patients with localized cancer is perioperative chemotherapy (for esophageal or esophagogastric junction adenocarcinoma only), preoperative chemoradiation, or definitive chemoradiation. For preoperative chemoradiation or definitive chemoradiation for localized cancer, cisplatin and 5-fluorouracil is the most studied and commonly used chemotherapeutic regimen. Cisplatin has also been studied and used in combination with taxanes (paclitaxel, docetaxel) and irinotecan. Mitomycin and gemcitabine have been used in second-line therapy as well. Cisplatin is often used interchangeably with oxaliplatin or carboplatin. 5-fluorouracil (5-FU) has been substituted with capecitabine. In patients with distal esophageal or gastroesophageal junction adenocarcinoma, perioperative chemotherapy based on ECF (epirubicin, cisplatin, and 5-FU) or ECF modifications (oxaliplatin, capecitabine) are used in a neoadjuvant approach followed by surgery then additional chemotherapy. Postoperative chemoradiation with capecitabine or 5-FU and leucovorin have been used in adenocarcinoma patients who did not receive preoperative treatment. Finally, in metastatic or locally advanced adenocarcinoma, trastuzumab has been used in patients with HER2-neu overexpression. Specific dosages, infusion forms, and time-schedules are available in the most recent NCCN guidelines for esophageal and esophagogastric junction cancers ${ }^{32}$ and will not be discussed further here.

\section{Principles of radiation}

Radiation treatment can be given with preoperative, postoperative, definitive, or palliative intent. In general, radiation is most effective when given concomitantly with chemotherapy. Based on randomized data that is discussed below, radiation therapy alone should be reserved for palliation or when patients are unfit to receive concomitant chemotherapy. For preoperative therapy and for patients undergoing definitive therapy, 45.0-50.4 Gy is delivered in 1.8-2.0 Gy/day fractions. Basic radiation principles to minimize damage to adjacent organs and monitor for intolerable treatment toxicities are followed. Standard blocking measures are employed to minimize radiation exposure to the heart, lung, spinal cord, liver, and kidneys. Gross tumor volume should include primary tumor and involved nodal areas. Clinical target volume should encompass areas at risk for microscopic disease. Radiation field planning goals include a proximal and distal margin of $5 \mathrm{~cm}$, with a radial margin of $1.5-2.0 \mathrm{~cm} \cdot{ }^{33-35}$

\section{Principles of surgery}

Multiple surgical options exist for performing esophagectomy or esophagogastrectomy. Each technique carries its own advantages and disadvantages with respect to exposure, location of anastomosis, and potential complications. Surgical approaches are summarized in Table 4. The most common approaches are the Ivor-Lewis or transthoracic technique, which involves right thoracotomy with midline laparotomy and an anastomosis of the gastric conduit to the proximal mediastinal esophagus in the apical right chest, and the transhiatal esophagogastrectomy, which entails a midline laparotomy and left cervical incision and anastomosis of the gastric conduit to the cervical esophagus. The McKeown technique involves right thoracotomy, laparotomy, and cervical anastomosis. All of these operations have been described as being performed in a minimally invasive fashion utilizing a combination of laparoscopic and thoracoscopic approaches. Left transthoracic or thoracoabdominal esophagectomy involves a contiguous incision involving

Table 4 Operative approaches for resectable esophageal or gastroesophageal junction cancer

\begin{tabular}{|c|c|c|}
\hline Operation name & Incision location & $\begin{array}{l}\text { Anastomosis } \\
\text { location }\end{array}$ \\
\hline $\begin{array}{l}\text { Ivor Lewis } \\
\text { esophagogastrectomy }\end{array}$ & $\begin{array}{l}\text { Laparotomy, right } \\
\text { thoracotomy }\end{array}$ & Right chest \\
\hline $\begin{array}{l}\text { Transhiatal } \\
\text { esophagogastrectomy }\end{array}$ & Laparotomy, cervical & Left neck \\
\hline $\begin{array}{l}\text { McKeown } \\
\text { esophagogastrectomy }\end{array}$ & $\begin{array}{l}\text { Laparotomy, right } \\
\text { thoracotomy, cervical }\end{array}$ & Left neck \\
\hline $\begin{array}{l}\text { Left transthoracic or } \\
\text { thoracoabdominal }\end{array}$ & $\begin{array}{l}\text { Laparotomy, left } \\
\text { thoracotomy or extended } \\
\text { thoracoabdominal incision }\end{array}$ & $\begin{array}{l}\text { Left chest } \\
\text { or neck }\end{array}$ \\
\hline
\end{tabular}

Notes: 'Each of these operations can been done with a minimally invasive approach. For minimally invasive approaches, laparoscopy and/or a limited laparotomy and thoracoscopy or limited thoracotomy may be used. Minimally invasive approaches may also be done with robotic assistance; bfor distal esophageal or gastroesophageal junction tumors only. 
both the chest and abdomen and are usually reserved for true gastroesophageal junction tumors or large proximal gastric cancers (Siewert classification type II or III). Of note, the type of surgical esophagectomy performed has never been shown to influence oncologic or survival outcome. Surgeon experience and comfort with a particular procedure and the ability to obtain proper margins with adequate nodal sampling is of higher importance. A $10 \mathrm{~cm}$ proximal esophageal margin and $5 \mathrm{~cm}$ distal gastric margin should be obtained to ensure negative final microscopic margins. ${ }^{36,37}$ Thus, cervical cancers less than $5 \mathrm{~cm}$ from the cricopharyngeus should receive definitive chemoradiation treatment as surgical cure is rare and, like other head and neck cancers, are squamous cell histology, which are responsive to chemoradiation.

While the exact number of nodes to be retrieved has not been determined, survival and adequate staging are optimized by adequate nodal sampling. ${ }^{38}$ Per NCCN and AJCC guidelines, at least 15 regional lymph nodes should be retrieved and examined. This can be derived from standard or en-bloc nodal collection. Nodal stations harvested should be those in the standard operative field encountered during esophagogastrectomy. Distant nodal stations outside the standard resection field are considered as metastatic disease and a contraindication to surgical resection. As preoperative chemoradiation affects nodal harvest, the number of nodes that should be examined following preoperative treatment is not defined, but 15 nodes should be sought out by the surgeon and pathologist reviewing the specimen.

Continuity of the gastrointestinal tract should be restored with a gastric conduit based on the right gastric and gastroepiploic arteries. In patients with prior gastric surgery or inadequate gastric blood supply, a colon or, rarely, a small bowel conduit may be used but with associated increased perioperative morbidity. A gastric drainage procedure in the form of a pyloroplasty or pyloromyotomy is performed to prevent postoperative gastric retention and need for early surgical or endoscopic intervention. In experienced hands and at high volume centers, the mortality from esophagectomy is $4 \%-10 \%$ and morbidity is $26 \%-41 \%$. $^{39-41}$

\section{Management of localized esophageal cancer}

Early detection of localized esophageal cancer allows for several treatment options. Carcinoma in situ (Tis) or high-grade dysplasia should be treated with endoscopic mucosal resection (EMR) and radiofrequency ablation of concomitant Barrett's esophagus followed by vigilant endoscopic surveillance, as detailed below. Treatment options for patients with T1N0M0 disease have advanced recently. All T1N0M0 patients should undergo endoscopic biopsy with EMR, if possible. EMR with negative margins and ablation of adjacent tissue harboring Barrett's metaplasia has become a standard therapy option for patients with T1a disease. As described previously, these lesions almost never have nodal involvement. Studies have shown local disease control of $93 \%-99 \%$ with EMR in T1a disease. ${ }^{42-45}$ Per NCCN guidelines, patients treated with EMR for T1 a disease or Tis disease should have surveillance endoscopy every 3 months for 1 year, and then annually. In the initial screening of these patients and during follow-up of treatment, adjuncts to standard endoscopic screening utilizing magnification technology, narrow-band imaging, and chromoendoscopy have proven helpful in select patients. ${ }^{46}$ Local recurrence can be managed by repeat EMR unless the submucosa has been breached. A more recent development in treatment of localized superficial esophageal adenocarcinoma and squamous cell carcinoma and precursor lesions is endoscopic submucosal dissection. This technique allows for more extensive resection of larger lesions and definitive treatment of precursor lesions including Barrett's metaplasia and squamous dysplasia. ${ }^{47,48}$ Esophagectomy is also an acceptable treatment option at any point for $\mathrm{T} 1 \mathrm{a}$ lesions. The advantage of esophagectomy in T1a lesions is definitive local control of the primary lesion and at-risk adjacent mucosa, thereby obviating the need for ongoing endoscopic surveillance compared with the main disadvantage being the morbidity and mortality associated with surgery. T1b lesions, on the other hand, are much more likely to exhibit nodal spread and should be treated with esophagectomy.

The next grouping of tumors is a wide classification that falls under a similar treatment algorithm. This group consists of patients with localized and, therefore, treatable esophageal cancer. The spectrum of T1b-3, N1-3, M0 esophageal cancer should receive multimodality combination therapy. Several treatment algorithms are available depending on physician and patient preference, tumor biology and location, and patient comorbidities. They may receive neoadjuvant chemoradiation followed by esophagectomy, definitive chemoradiation followed by salvage esophagectomy for persistent or recurrent disease, preoperative chemotherapy followed by esophagectomy and adjuvant chemotherapy (for distal esophageal and gastroesophageal junction adenocarcinoma only), or esophagectomy with adjuvant chemoradiation. Single modality treatment should be avoided, as outcomes are inferior. This applies to chemotherapy, radiation therapy, 
and surgery alone. NCCN guidelines further detail treatment regimens in either of these scenarios. ${ }^{32}$ Chemotherapeutic regimens vary depending on definitive, neoadjuvant, or adjuvant intent.

Preoperative chemoradiation followed by esophagectomy or definitive chemoradiation with salvage surgery for persistent or recurrent disease have become the most common approaches to treatment. While the latter is endorsed as an acceptable treatment option per the NCCN guidelines, the former remains the preferred approach pending maturation of the data from several recent studies looking at treatment of esophageal squamous and adenocarcinoma with definitive chemoradiation rather than proceeding directly to surgery following completion of preoperative treatment. Of these two approaches, preoperative chemoradiation with 45005040 cGy of radiation and concurrent chemotherapy is most commonly used, and recent meta-analyses support this recommendation with improved 3-year mortality and reduced locoregional recurrence. ${ }^{49-51}$ Moreover, recent studies, including the CROSS trial out of the Netherlands, have shown an improvement in survival with preoperative chemoradiation therapy with carboplatin and paclitaxel compared with surgery alone in patients with adenocarcinoma of the esophagus or gastroesophageal junction. In the case of this study, median was 49 months in those patients receiving preoperative chemoradiation, compared with 26 months in the surgery-alone arm. Furthermore, 1-, 2-, and 3-year survivals were improved. Complete pathologic response was seen in $30 \%$ of patients. R0 resection was $65 \%$ of the surgery-alone patients compared with $92 \%$ with preoperative therapy. ${ }^{52}$ As such, patients with localized, intermediate stage esophageal and gastroesophageal junction adenocarcinoma should not proceed directly to esophagectomy, but rather treated at least with combined chemoradiation prior to consideration of surgery. A recent meta-analysis of 4188 patients confirmed this observation..$^{53}$ The hazard ratio (HR) for all-cause mortality for neoadjuvant chemoradiotherapy in this comprehensive review was 0.78 (95\% confidence interval [CI]: $0.70-0.88$; $P<0.0001)$; the HR for squamous-cell carcinoma only was 0.80 (95\% CI: $0.68-0.93 ; P=0.004)$ and for adenocarcinoma only was 0.75 (95\% CI: $0.59-0.95 ; P=0.02)$. The HR for all-cause mortality for neoadjuvant chemotherapy was 0.87 (95\% CI: $0.79-0.96 ; P=0.005$ ); the HR for squamous-cell carcinoma only was 0.92 (95\% CI: $0.81-1.04 ; P=0.18)$ and for adenocarcinoma only was 0.83 (95\% CI: $0.71-0.95$; $P=0.01)$. Thus, a strategy of preoperative chemotherapy without radiation is an appropriate option for patients with adenocarcinoma but not for squamous cell carcinoma where the addition of radiation therapy to preoperative chemotherapy is needed.

As discussed previously, new data is arriving comparing squamous cell and adenocarcinoma of the esophagus. It appears that definitive chemoradiation is equivalent to neoadjuvant treatment followed by esophagectomy for squamous cell cancer of the esophagus. ${ }^{54,55}$ With this in mind, a strategy of definitive chemoradiation with careful endoscopic and radiographic assessment of response has gained acceptance for squamous cell carcinoma, as patients with a squamous cell cancer that have an endoscopic complete response are more likely to have a pathologic complete response at esophagectomy as compared to adenocarcinoma. The added value of surgery following chemoradiation in the setting of localized esophageal squamous cell cancer remains unclear. There is insufficient data to support the same statement for adenocarcinoma at this time. Hence, surgical resection is still recommended in this clinical scenario.

Whether chemoradiation is employed as a primary treatment strategy or as a preoperative approach, posttreatment evaluation with follow-up CT scan or, preferably, PET-CT, and upper endoscopy with biopsy is imperative among patients who are candidates for surgical resection. For patients in whom a neoadjuvant approach was planned, esophagectomy is the preferred next step in patients with either no evidence of disease or persistent localized disease. Alternatively, observation may be undertaken if neither PET-CT nor endoscopy with biopsy shows residual disease. When definitive chemoradiation is employed, the same follow-up algorithm is employed with the exception of planned observation in patients with no disease present following treatment. In these patients, a history and physical every 3-6 months for 1-2 years, then 6-12 months for 3-5 years, then annually is done. As clinically indicated by patient symptoms, repeat radiographic imaging and endoscopy with biopsy is performed. For patients with localized recurrence, salvage esophagectomy is recommended and palliative systemic treatment or supportive measures in the case of metastatic or locally unresectable disease.

While patients with T1b, N1, or T2 or higher with any regional node involvement are best treated with multimodality therapy, proceeding directly to esophagectomy once the diagnosis of localized esophageal cancer is made is acceptable. Further treatment depends of the surgical margins, nodal status, and histology. In patients undergoing complete resection (R0 resection) with squamous cell carcinoma, no further treatment is indicated. If during follow-up clinical examination, CT or PET-CT, and/or endoscopy with biopsy 
a locoregional recurrence is observed, patients should then be offered concurrent chemoradiation, chemotherapy, or best supportive care. In patients with localized esophageal adenocarcinoma who have undergone $\mathrm{R} 0$ resection as primary treatment, observation is indicated for $\mathrm{T} 1$ or $\mathrm{T} 2$ and $\mathrm{N} 0$ tumors. In patients with high-risk T2, N0 tumors (poorly differentiated histology, lymphovascular or neurovascular invasion, younger age), T3, N0 or any tumor with positive regional lymph node involvement (N1-3), postoperative chemoradiation is indicated. ${ }^{56}$ In patients with microscopic (R1) or macroscopic (R2) residual adenocarcinoma or squamous cell carcinoma following primary surgical treatment, chemoradiation is indicated.

Following completion of definitive treatment, surveillance guidelines set forth by the NCCN call for history and physical examination every 3-6 months following treatment for the first 1-2 years, then every 6-12 months for 3-5 years, then annually thereafter. Current survival laboratory or imaging studies should be performed as clinically indicated. Complications such as anastomotic stricture should be managed as needed with endoscopic balloon dilations with or without steroid injection. Other common issues such as dumping syndrome and poor nutritional intake can usually be managed with lifestyle modification, temporary nutritional support, and medications.

Treatment options for patients who are medically unfit for surgery, choose not to undergo surgery, or have unresectable T4 disease are limited to chemotherapy and radiation therapy or best supportive care. For patients with localized esophageal cancer who are unfit for surgery, chemotherapy and radiation therapy is the best treatment option as long as the patient's performance status and medical comorbidities permit treatment. For patients with metastatic disease, systemic chemotherapy is the best option. For patients who decline treatment or are unfit for systemic treatment, best supportive, palliative care should be implemented. Current stage-specific survival for esophageal cancer is illustrated in Table 3 and Figure 4.

\section{Supportive care}

Unresectable esophageal cancer, patients with stage 4 or metastatic disease, and cancer arising in patients medically unfit for treatment present a grave clinical dilemma. In patients with unresectable (T4b or bulky distant nodal disease), chemotherapy or chemoradiation or best supportive care should be considered. In patients with metastatic disease, chemotherapy as palliative treatment can be considered as long as the patient is medically fit for treatment. Alternatively, best supportive care is an option.
Additional palliative measures should address common complications of the disease process, including dysphagia and nutritional failure. Dysphagia is the most common symptom of advanced disease. The clinical spectrum of dysphagia ranges from having difficulty with larger pieces of solid food to the inability to tolerate one's own salivary secretions. Techniques for management of dysphagia include endoscopic dilatation and/or stenting, radiation therapy, brachytherapy, chemotherapy, or surgery. Percutaneous endoscopic gastrostomy (PEG) is also a viable palliative option for unresectable tumors. Patient specific factors should be considered when deciding which modality to choose. Patients presenting with complete obstruction will likely require surgical gastrostomy or jejunostomy tube placement for enteral access. Endoscopic luminal restoration via dilatation or stenting, brachytherapy, or radiation should initially be attempted if possible.

Pain should be managed in a controlled setting with referral to chronic pain specialists if indicated. Bleeding from the tumor or invasion can be approached with endoscopic techniques, radiation, or rarely, surgery. A multidisciplinary approach is just as important to supportive care as it is to curative intent. Given the high rate of morbidity associated with surgery, a palliative esophagectomy in patients with metastatic or untreatable disease should not be performed in light of the success of other far less invasive palliative treatment modalities.

\section{Conclusion}

Esophageal cancer remains a lethal disease entity. The biologic characteristics of the disease have evolved from squamous cell carcinoma predominant disease to adenocarcinoma. Death rates and incidence continue to increase, especially with regard to adenocarcinoma. Recent advances in multimodality treatment show promise in improving outcomes and survival while decreasing morbidity. Proper staging and workup is vital to determine treatment strategies and goals. Once determined, a multidisciplinary approach should be employed for treatment and surveillance. Preferably, evaluation and treatment options for each patient with localized esophageal cancer should be discussed in a multidisciplinary treatment planning conference. In general, early stage T1 tumors are best managed by endoscopic modalities (superficial T1a lesions) or esophagogastrectomy (T1b) if possible. Lesions extending into and beyond the submucosa and those with nodal involvement seen on preoperative staging should be treated with combined multimodality therapy in a high volume cancer center. Unresectable disease or patients unfit 
for chemotherapy, radiation therapy, and/or surgery should be considered for palliation.

\section{Disclosure}

The authors report no conflicts of interest in this work.

\section{References}

1. Jemal A, Siegel R, Xu J, Ward E. Cancer statistics, 2010. CA Cancer J Clin. 2010;60(5):277-300.

2. Bollschweiler E, Wolfgarten E, Gutschow C, Holscher AH. Demographic variations in the rising incidence of esophageal adenocarcinoma in white males. Cancer. 2001;92(3):549-555.

3. Brown L, Dewesa S, Chow W. Incidence of adenocarcinoma of the esophagus among white Americans by sex, stage, and age. J Natl Cancer Inst. 2008;100(16):1223-1232.

4. Cossentino MJ, Wong RK. Barrett's esophagus and risk of esophageal adenocarcinoma. Semin Gastrointest Dis. 2003;14(3):128-135.

5. Esophagus and esophagogastric junction. In: Edge SB, Byrd DR, Compton CC, et al, editors. AJCC Cancer Staging Manual. 7th ed. New York, NY: Springer; 2010:103-111.

6. Ajani JA, Barthel JS, Bekaii-Saab T, et al. Esophageal cancer. $J$ Natl Compr Canc Netw. 2008;6(9):818-849.

7. Siewert JR, Stein HJ. Classification of adenocarcinoma of the esophagogastric junction. Br J Surg. 1998;85(11):1457-1459.

8. Lund O, Hasenkam JM, Aagaard MT, Kimose HH. Time-related changes in characteristics of prognostic significance in carcinomas of the oesophagus and cardia. Br J Surg. 1989;76(12):1301-1307.

9. National Cancer Institute. Surveillance epidemiology and end results. Available from: http://seer.cancer.gov/statfacts/html/esoph.html. Accessed May 17, 2012.

10. Wijnhoven BP, Tran KT, Esterman A, et al. An evaluation of prognostic factors and tumor staging of resected carcinoma of the esophagus. Ann Surg. 2007;245(5):717-725.

11. Cen P, Hofstetter WL, Correa AM, et al. Lymphovascular invasion as a tool to further subclassify T1b esophageal adenocarcinoma. Cancer. 2008;112(5):1020-1027.

12. Barbour AP, Rizk NP, Gonen M, et al. Lymphadenectomy for adenocarcinoma of the gastroesophageal junction (GEJ): impact of adequate staging on outcome. Ann Surg Oncol. 2007;14(2):306-316.

13. Sepesi B, Watson TJ, Zhou D, et al. Are endoscopic therapies appropriate for superficial submucosal esophageal adenocarcinoma? An analysis of esophagectomy specimens. J Am Coll Surg. 2010;210(4):418-427.

14. Raja S, Rice TW, Goldblum JR, et al. Esophageal submucosa: the watershed for esophageal cancer. J Thorac Cardiovasc Surg. 2011;142(6): 1403-1411. e 1.

15. O'Riordan JM, Rowley S, Murphy JO, et al. Impact of solitary involved lymph node on outcome in localized cancer of the esophagus and esophagogastric junction. J Gastrointest Surg. 2007;11(4):493-499.

16. Thompson SK, Ruszkiewicz AR, Jamieson GG, et al. Improving the accuracy of TNM staging in esophageal cancer: a pathological review of resected specimens. Ann Surg Oncol. 2008;15(12): 3447-3458.

17. Bhamidipati CM, Stukenborg GJ, Thomas CJ, Lau CL, Kozower BD, Jones DR. Pathologic lymph node ratio is a predictor of survival in esophageal cancer. Ann Thorac Surg. May 22, 2012. [Epub ahead of print.]

18. Hsu WH, Hsu PK, Hsieh CC, Huang CS, Wu YC. The metastatic lymph node number and ratio are independent prognostic factors in esophageal cancer. J Gastrointest Surg. 2009;13(11):1913-1920.

19. Akutsu Y, Shuto K, Kono T, et al. The number of pathologic lymph nodes involved is still a significant prognostic factor even after neoadjuvant chemoradiotherapy in esophageal squamous cell carcinoma. J Surg Oncol. 2012;105(8):756-760.
20. Karnofsky DA, Burchenal JH. The clinical evaluation of chemotherapeutic agents in cancer. In: MacLeod CM, editor. Evaluation of Chemotherapeutic Agents. New York, NY: Columbia University Press; 1949:191-205.

21. Oken MM, Creech RH, Tormey DC, et al. Toxicity and response criteria of the eastern cooperative oncology group. Am J Clin Oncol. 1982;5: 649-655.

22. Rasanen JV, Sihvo EI, Knuuti MJ, et al. Prospective analysis of accuracy of positron emission tomography, computed tomography, and endoscopic ultrasonography in staging of adenocarcinoma of the esophagus and the esophagogastric junction. Ann Surg Oncol. 2003; 10(8):954-960.

23. Lowe VJ, Booya F, Fletcher JG, et al. Comparison of positron emission tomography, computed tomography, and endoscopic ultrasound in the initial staging of patients with esophageal cancer. Mol Imaging Biol. 2005;7(6):422-430.

24. Downey RJ, Akhurst T, Ilson D, et al. Whole body 18FDG-PET and the response of esophageal cancer to induction therapy: results of a prospective trial. J Clin Oncol. 2003;21(3):428-432.

25. Shimpi RA, George J, Jowell P, Gress FG. Staging of esophageal cancer by EUS: staging accuracy revisited. Gastrointest Endosc. 2007;66(3): 475-482.

26. Pech O, Gunter E, Dusemund F, et al. Accuracy of endoscopic ultrasound in preoperative staging of esophageal cancer: results from a referral center for early esophageal cancer. Endoscopy. 2010;42(6): 456-461.

27. Smith BR, Chang KJ, Lee JG, Nguyen NT. Staging accuracy of endoscopic ultrasound based on pathologic analysis after minimally invasive esophagectomy. Am Surg. 2010;76(11):1228-1231.

28. Choi J, Kim SG, Kim JS, et al. Comparison of endoscopic ultrasonography (EUS), positron emission tomography (PET), and computed tomography (CT) in the preoperative locoregional staging of resectable esophageal cancer. Surg Endosc. 2010;24(6):1380-1386.

29. Walker AJ, Spier BJ, Perlman SB, et al. Integrated PET/CT fusion imaging and endoscopic ultrasound in the pre-operative staging and evaluation of esophageal cancer. Mol Imaging Biol. 2011;13(1): $166-171$.

30. Birkmeyer JD, Siewers AE, Finlayson EV, et al. Hospital volume and surgical mortality in the United States. N Engl J Med. 2002;346(15): $1128-1137$.

31. Birkmeyer NJ, Goodney PP, Stukel TA, et al. Do cancer centers designated by the National Cancer Institute have better surgical outcomes? Cancer. 2005;103(3):435-441.

32. National Comprehensive Cancer Network. Clinical practice guidelines in oncology. Esophageal and esophagogastric junction cancers. Version 2. 2012. Available from: https://subscriptions.nccn.org/gl_login. aspx?ReturnURL=http://www.nccn.org/professionals/physician_gls/pdf/ esophageal.pdf. Accessed May 17, 2012.

33. Glasgow RE, Ilson DH, Hayman JA, Gerdes H, Mulcahy MF, Ajani JA. Modern approaches to localized cancer of the esophagus. J Natl Compr Canc Netw. 2011;9(8):902-911.

34. Czito BG, Denittis AS, Willett CG. Esophagus. In: Halperin EC, Perez CA, Brady LW, Wazer DE, Freeman C, Prosnitz LR, editors. Perez and Brady's Principles and Practice of Radiation Oncology. 5th ed. Philadelphia, PA: Lippincott Williams \& Wilkins; 2007: 1131-1153.

35. International Commission on Radiation Units and Measurements (ICRU). Prescribing, recording and reporting photon beam therapy. ICRU Report 62. Bethesda, MD: ICRU; 1999.

36. Wong J. Esophageal resection for cancer: the rationale of current practice. Am J Surg. 1987;153(1):18-24.

37. Barbour AP, Rizk NP, Gonen M, et al. Adenocarcinoma of the gastroesophageal junction: influence of esophageal resection margin and operative approach on outcome. Ann Surg. 2007;246(1):1-8.

38. Rizk NP, Ishwaran H, Rice TW, et al. Optimum lymphadenectomy for esophageal cancer. Ann Surg. 2010 Jan;251(1):46-50. 
39. Dimick JB, Wainess RM, Upchurch GR Jr, et al. National trends in outcomes for esophageal resection. Ann Thorac Surg. 2005;79(1):212-216; discussion 217-218.

40. Enzinger PC, Mayer RJ. Esophageal cancer. $N$ Engl J Med. 2003; 349(23):2241-2252.

41. Wright CD, Kucharczuk JC, O'Brien SM, et al. Predictors of major morbidity and mortality after esophagectomy for esophageal cancer: a Society of Thoracic Surgeons General Thoracic Surgery Database risk adjustment model. J Thorac Cardiovasc Surg. 2009;137(3):587-595; discussion 596.

42. Ell C, May A, Pech O, et al. Curative endoscopic resection of early esophageal adenocarcinomas (Barrett's cancer). Gastrointest Endosc. 2007;65(1):3-10.

43. Pech O, May A, Gossner L, et al. Curative endoscopic therapy in patients with early esophageal squamous-cell carcinoma or high-grade intraepithelial neoplasia. Endoscopy. 2007;39(1):30-35.

44. Peters FP, Kara MA, Rosmolen WD, et al. Endoscopic treatment of high-grade dysplasia and early stage cancer in Barrett's esophagus. Gastrointest Endosc. 2005;61(4):506-514.

45. Pouw RE, Peters FP, Sempoux C, et al. Stepwise radical endoscopic resection for Barrett's esophagus with early neoplasia: report on a Brussels' cohort. Endoscopy. 2008;40(11):892-898.

46. Shahid MW, Wallace MB. Endoscopic imaging for the detection of esophageal dysplasia and carcinoma. Gastrointest Endosc Clin N Am. 2010;20(1):11-24, v.

47. Honda K, Akiho H. Endoscopic submucosal dissection for superficial esophageal squamous cell neoplasms. World J Gastrointest Pathophysiol. 2012;3(2):44-50

48. Ono S, Fujishiro M, Koike K. Endoscopic submucosal dissection for superficial esophageal neoplasms. World J Gastrointest Endosc. 2012; 4(5):162-166.

49. Fiorica F, Di Bona D, Schepis F, et al. Preoperative chemoradiotherapy for oesophageal cancer: a systematic review and meta-analysis. Gut. 2004;53(7):925-930.

50. Gebski V, Burmeister B, Smithers BM, et al. Survival benefits from neoadjuvant chemoradiotherapy or chemotherapy in oesophageal carcinoma: a meta-analysis. Lancet Oncol. 2007;8(3): 226-234.

51. Jin HL, Zhu H, Ling TS, et al. Neoadjuvant chemoradiotherapy for resectable esophageal carcinoma: a meta-analysis. World J Gastroenterol. 2009;15(47):5983-5991.
52. Gaast AV, van Hagen P, Hulshof M, et al. Effect of preoperative concurrent chemoradiotherapy on survival of patients with resectable esophageal or esophagogastric junction cancer: results from a multicenter randomized phase III study. J Clin Oncol. 2010;28:15s.

53. Sjoquist KM, Burmeister BH, Smithers BM, et al; for the Australasian Gastro-Intestinal Trials Group. Survival after neoadjuvant chemotherapy or chemoradiotherapy for resectable oesophageal carcinoma: an updated meta-analysis. Lancet Oncol. 2011;12(7):681-692.

54. Stahl M, Stuschke M, Lehmann N, et al. Chemoradiation with and without surgery in patients with locally advanced squamous cell carcinoma of the esophagus. J Clin Oncol. 2005;23(10):2310-2317.

55. Bedenne L, Michel P, Bouche O, et al. Chemoradiation followed by surgery compared with chemoradiation alone in squamous cancer of the esophagus: FFCD 9102. J Clin Oncol. 2007;25(10):1160-1168.

56. Kleinberg L, Knisely JP, Heitmiller R, et al. Mature survival results with preoperative cisplatin, protracted infusion 5-fluorouracil, and 44-Gy radiotherapy for esophageal cancer. Int $J$ Radiat Oncol Biol Phys. 2003;56(2):328-334.

57. American College of Surgeons Cancer Programs. National Cancer Data Base. Available from: http://www.facs.org/cancer/ncdb. Accessed August 25, 2012.

58. Howlader N, Noone AM, Krapcho M, et al. SEER Cancer Statistics Review, 1975-2009 (Vintage 2009 Populations). Bethesda, MD: National Cancer Institute; 2012. Available from: http://www.aboutcancer.com/ esophagus_survival_curve_seer.gif. Accessed on January 6, 2012.

59. Yoon HH, Khan M, Shi Q, et al. The prognostic value of clinical and pathologic factors in esophageal adenocarcinoma: a mayo cohort of 796 patients with extended follow-up after surgical resection. Mayo Clin Proc. 2010;85(12):1080-1089.

60. Rice TW, Rusch VW, Ishwaran H, Blackstone EH; for the Worldwide Esophageal Cancer Collaboration. Cancer of the esophagus and esophagogastric junction: data-driven staging for the seventh edition of the American Joint Committee on Cancer/International Union Against Cancer Cancer Staging Manuals. Cancer. 2010;116(16):3763-3773.

61. Mariette C, Piessen G, Briez N, Gronnier C, Triboulet JP. Oesophagogastric junction adenocarcinoma: which therapeutic approach? Lancet Oncol. 2011;12(3):296-305.
Cancer Management and Research

\section{Publish your work in this journal}

Cancer Management and Research is an international, peer-reviewed open access journal focusing on cancer research and the optimal use of preventative and integrated treatment interventions to achieve improved outcomes, enhanced survival and quality of life for the cancer patient The journal welcomes original research, clinical \& epidemiological

\section{Dovepress}

studies, reviews \& evaluations, guidelines, expert opinion \& commentary, case reports \& extended reports. The manuscript management system is completely online and includes a very quick and fair peerreview system, which is all easy to use. Visit http://www.dovepress.com/ testimonials.php to read real quotes from published authors. 